JAFIB

Original Research

Journal of Atrial Fibrillation

WWW. jafib.com

\title{
Rate Versus Rhythm Control in Patients with Normal to Mild Left Atrial Enlargement: Insights from the AFFIRM Trial
}

\author{
Talal Alzahrani ${ }^{1}$, James McCaffrey ${ }^{1}$, Marco Mercader ${ }^{1}$, Allen Solomon ${ }^{1}$ \\ ${ }^{1}$ Division of Cardiology, Department of Medicine, George Washington University, Washington, DC.
}

\begin{abstract}
Background: Atrial fibrillation is the most commonly encountered sustained arrhythmia and is associated with significant morbidity and mortality. Several trials have demonstrated that no mortality benefit exists when choosing a rhythm-control strategy over a rate-control strategy, with some trials suggesting an increase in mortality. Using the AFFIRM trial database we sought to determine the effect of rhythm control strategy in patients with normal or mild atrial enlargement.

Methods: AFFIRM Trial database was used to evaluate the effect of rhythm-control strategy compared to rate-control strategy in a subgroup of patients with normal to mild left atrial (LA) enlargement. The primary outcome measures of this study were all-cause mortality, cardiovascular mortality, non-cardiovascular mortality, and hospitalization/ED visit.

Results: We identified a subgroup of subjects from the AFFIRM trial with normal or mild LA enlargement ( $n=2022$ of 4060 total subjects). Subjects in the rhythm-control group $(n=1022)$ had an increased risk of all-cause mortality by $34 \%(R R 1.34,95 \% \mathrm{Cl} 1.08-1.67 ; \mathrm{P}=0.007)$ and hospitalization/ED visits by $10 \%$ (RR 1.10, 95\% Cl 1.05-2.16; $P=<0.001)$ compared to rate control group $(n=1000)$.

Conclusion: This study demonstrated that rhythm-control strategy increases the risk of mortality and hospitalization in a subgroup of patients with normal to mild atrial enlargement compared to rate-control strategy. Amiodarone use in this subgroup of patients likely drove these findings.
\end{abstract}

\section{Introduction}

The concept that "atrial fibrillation begets atrial fibrillation" is well described and poses a challenge to physicians hoping to restore sinus rhythm ${ }^{[1,2]}$.Atrial remodeling occurs on an electrical, contractile, and structural level while patients are in atrial fibrillation $(\mathrm{AF})^{[3,13]}$. These changes make patient's atria more susceptible to developing episodes of AF and make the restoration of sinus rhythm more unlikely ${ }^{[14-24]}$. Left atrial (LA) enlargement is a typical structural change observed as a result of long-standing $\mathrm{AF}$ and predicts failure to maintain sinus rhythm ${ }^{[25-300 .}$.

Atrial fibrillation is the most commonly encountered sustained arrhythmia and is associated with significant morbidity and mortality [31,37]. Despite the increased mortality that comes with AF, multiple trials have demonstrated that no mortality benefit exists when choosing a rhythm-control strategy over a rate-control strategy, with some trials suggesting an increase in mortality ${ }^{[38-44]}$. The Atrial Fibrillation Follow-up Investigation of Rhythm Management (AFFIRM) study compared rhythm-control and rate-control strategies for the treatment of atrial fibrillation ${ }^{[40]}$. The trial included

Key Words

Atrial Fibrillation, Rhythm Management, Rate Control, Atrial Size.

Corresponding Author

Talal Alzahrani,

2150 Pennsylvania Ave NW, Fourth floor,

Washington, DC patients at least 65 years of age or at increased risk for stroke. The rhythm-control group was primarily treated using anti-arrhythmic drugs (AADs) and electrical cardioversion with a small percentage undergoing ablation. The AFFIRM investigators found that more patients in the rhythm-control group were hospitalized, had more adverse drug effects, and had a non-significant trend towards higher mortality compared to patients in the rate-control arm. The study's aim in AFFIRM trial was to compare strategies in a heterogeneous patients population with atrial fibrillation. As a result, the patients included in the trial had a wide range of atrial remodeling and structural changes.

Using the AFFIRM trial database we sought to determine the effect of a rhythm-control strategy in patients with normal or mild LA enlargement. The presence of LA enlargement was collected during the AFFIRM trial based on the LA dimension. We chose the size of LA as a surrogate marker for LA remodeling as it has been demonstrated to occur in patients with long-standing AF and predicts difficulties in maintaining sinus rhythm.

\section{Materials and Methods}

Study population

Data from the Atrial Fibrillation Follow-up Investigation of Rhythm Management (AFFIRM) trial were used in this study. The AFFIRM study was a multi-center randomized clinical trial comparing rhythm-control to rate-control for patients with atrial fibrillation. The patients included were those who were at least 
65 years of age or who had other risk factors for stroke or death. Additionally, patients included were those in which long-term treatment was warranted, were candidates for either treatment strategy, did not have contraindications to anticoagulation, and had a high likelihood of recurrent atrial fibrillation. In our study, patients from the AFFIRM trial who had normal or mild LA enlargement based on echocardiography were included in our study.

\section{Intervention}

The patients in AFFIRM trial were randomized to rhythm-control or rate-control strategies. In the rhythm-control arm, patients were maintained in sinus rhythm by AADs (class Ia, Ic or III), as well as electrical cardioversion, if necessary. The AADs were amiodarone, flecainide, dofetilide, propafenone, disopyramide, procainamide, quinidine, sotalol, and moricizine. In the rate-control strategy, the ventricular rate was controlled using beta-blockers, digoxin, and/ or calcium-channel blockers (verapamil and diltiazem). The target ventricular rate was $=<80$ beats per minute at rest and $=<110$ beats per minute during a six-minute walk test.

\section{Outcome}

Outcomes include all-cause mortality, cardiovascular mortality, non-cardiovascular mortality, and the rate of hospitalization.

\section{Statistical analysis}

Comparisons between the two treatment arms, rhythm-control strategy and rate-control strategy, were conducted between baseline demographic and health characteristics using chi-square test and student's t-test. Baseline demographic characteristics included age,

\section{Table 1: Baseline demographic and health characteristics. *}

\begin{tabular}{|c|c|c|c|}
\hline Characteristics & $\begin{array}{l}\text { Rhythm- } \\
\text { control } \\
(\mathrm{N}=1022)\end{array}$ & $\begin{array}{l}\text { Rate-control } \\
(\mathrm{N}=1000)\end{array}$ & P Val-ue \\
\hline Age (year) & $70 \pm 8$ & $70 \pm 8$ & 0.71 \\
\hline Female sex (\% of patients) & $42.47 \dagger$ & 47.60 & 0.02 \\
\hline Body mass index & $28 \pm 6$ & $29 \pm 6$ & 0.23 \\
\hline $\begin{array}{l}\text { Medical history (\% of patients) } \\
\text { - Diabetes (DM) } \\
\text { - Hypertension (HTN) } \\
\text { - Angina pectoris } \\
\text { - Myocardial infarction } \\
\text { - Coronary artery disease } \\
\text { - Coronary artery bypass graft } \\
\text { - Stroke or TIA } \\
\text { - Valvular heart disease } \\
\text { - Congestive heart failure } \\
\text { - Congenital heart disease } \\
\text { - Peripheral vascular disease } \\
\text { - Hepatic or renal disease } \\
\text { - Pulmonary disease } \\
\text { - First episode of atrial fibrillation (AF) } \\
\text { - Duration of qualifying of AF } \geq 2 \text { days }\end{array}$ & $\begin{array}{l}17.91 \\
70.06 \\
24.07 \\
15.95 \\
34.83 \\
10.08 \\
13.50 \\
10.76 \\
18.49 \\
0.39 \\
6.46 \\
4.99 \\
14.48 \\
36.32 \\
62.72\end{array}$ & $\begin{array}{l}19.80 \\
69.90 \\
21.40 \\
12.90 \\
32.70 \\
8.20 \\
14.50 \\
10.70 \\
19.10 \\
0.20 \\
6.30 \\
6.40 \\
12.30 \\
37.89 \\
64.00\end{array}$ & $\begin{array}{l}0.28 \\
0.94 \\
0.15 \\
0.05 \\
0.31 \\
0.14 \\
0.52 \\
0.96 \\
0.73 \\
0.43 \\
0.88 \\
0.17 \\
0.15 \\
0.47 \\
0.94\end{array}$ \\
\hline $\begin{array}{l}\text { Predominant cardiac diagnosis (\% of patients) } \\
\text { - Dilated non-ischemic cardiomyopathy }\end{array}$ & 54.11 & 55.60 & 0.50 \\
\hline $\begin{array}{l}\text { Blood pressure before run-in phase }(\mathrm{mm} \mathrm{Hg}) \\
\text { - Systolic } \\
\text { - Diastolic }\end{array}$ & $\begin{array}{l}136 \pm 19 \\
77 \pm 10\end{array}$ & $\begin{array}{l}136 \pm 19 \\
77 \pm 10\end{array}$ & $\begin{array}{l}0.97 \\
0.99\end{array}$ \\
\hline Ejection fraction (\%) & $57 \pm 8$ & $57 \pm 7$ & 0.55 \\
\hline The follow-up period (year) & $3.53 \pm 1.28$ & $3.54 \pm 1.28$ & 0.85 \\
\hline Change treatment strategy (\% of patients) & 0.26 & 0.11 & \\
\hline
\end{tabular}

\section{Table 2:}

The incidence of the outcomes in patients with normal and mild left atrial enlargement, rhythm control vs. rate control

$\begin{array}{llll}\begin{array}{l}\text { Rhythm- } \\ \text { control }\end{array} & \begin{array}{l}\text { Rate- } \\ \text { control }\end{array} & \begin{array}{l}\text { Relative Risk } \\ (\mathrm{N}=1022)\end{array} & \text { P-Value } \\ (\mathrm{N}=1000) & & \end{array}$

\begin{tabular}{lllll}
\multicolumn{5}{c}{ no. of patients (\%) } \\
All-cause mortality & $169(16.54)$ & $123(12.30)$ & $1.34(1.08-1.67)$ & 0.007 \\
Cardiovascular mortality & $74(7.24)$ & $75(7.50)$ & $0.97(0.71-1.32)$ & 0.823 \\
Non-cardiovascular mortality & $88(8.61)$ & $45(4.50)$ & $1.91(1.35-2.71)$ & $<0.001$ \\
Hospitalization/ED visit. & $796(77.89)$ & $707(70.70)$ & $1.10(1.05-1.16)$ & $<0.001$ \\
\hline
\end{tabular}

sex, and body mass index. Baseline health characteristics included past medical history, predominant cardiac diagnosis, blood pressure, and left ventricular ejection fraction.

An intention-to-treat analysis was used to compare outcomes of the two groups in patients with normal or mild LA enlargement. A chi-square test was used to test for differences between the treatment group's outcomes. A logistic regression model was also used to adjust for the difference in sex distribution between the two groups. The statistical analyses were performed using SAS version 9.4. All tests were conducted using an $\boldsymbol{\alpha}=0.05$ as the probability for a Type I error.

\section{Results}

\section{Baseline Characteristics}

The total number of subjects with normal or mild LA enlargement in the AFFIRM trial was 2,022 out of 4,060 subjects. Of the 2,022 subjects with normal or mild LA enlargement; 1,022 were assigned to the rhythm-control group, and 1,000 were assigned to the rate-control group. [Table 1] displays the descriptive baseline demographics and health characteristics of the two groups.

The mean $( \pm \mathrm{SD})$ age, body mass index, and ejection fraction were $70 \pm 8$ years, $28 \pm 6 \mathrm{~kg} / \mathrm{m} 2$, and $57 \pm 7 \%$, respectively. A total of 70 percent of the subjects had hypertension; 18.8 percent of the subjects had diabetes; 33.8 percent of subjects had coronary artery disease; 18.8 percent of the subjects had a history of congestive heart

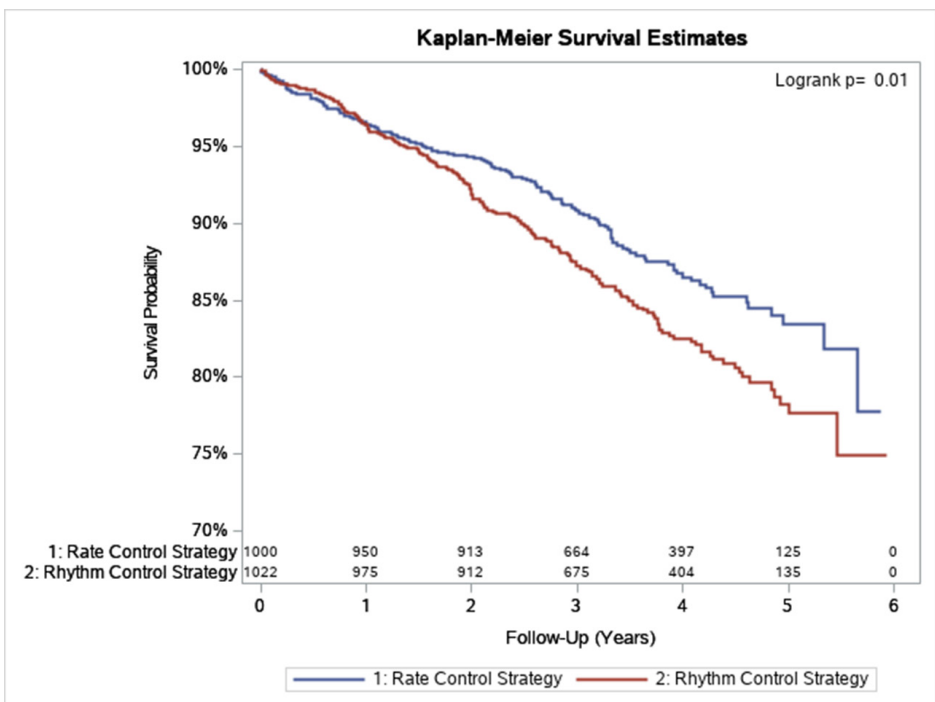

Figure 1

Kaplan-Meier Survival for All cause Mortality:Rhythm Control vs. Rate. 
The incidence of the outcomes in patients with normal and mild left atrial enlargement based on the initial antiarrhythmic therapy

\begin{tabular}{lllll}
\hline & $\begin{array}{l}\text { Amiodarone } \\
(\mathrm{N}=334)\end{array}$ & $\begin{array}{l}\text { Rate- } \\
\text { control } \\
(\mathrm{N}=1000)\end{array}$ & $\begin{array}{l}\text { Relative Risk } \\
(95 \% \mathrm{CI})\end{array}$ & P-value \\
All-cause mortality & $57(17.07)$ & $123(12.30)$ & $1.39(1.04-1.85)$ & 0.027 \\
Cardiovascular mortality & $23(6.89)$ & $75(7.50)$ & $0.92(0.59-1.44)$ & 0.710 \\
Non-cardiovascular mor-tality & $32(9.58)$ & $45(4.50)$ & $2.13(1.38-3.29)$ & 0.001 \\
& $\begin{array}{l}\text { Sotalol } \\
(\mathrm{N}=322)\end{array}$ & $\begin{array}{l}\text { Rate-control } \\
(\mathrm{N}=1000)\end{array}$ & $\begin{array}{l}\text { Relative Risk } \\
(95 \% \mathrm{Cl})\end{array}$ & P-value \\
& $43(13.35)$ & $123(12.30)$ & $1.09(0.79-1.50)$ & 0.620 \\
All-cause mortality & $16(4.97)$ & $75(7.50)$ & $0.66(0.39-1.12)$ & 0.119 \\
Cardiovascular mortality & $24(7.43)$ & $45(4.50)$ & $1.66(1.03-2.67)$ & 0.038 \\
\hline Non-cardiovascular mor-tality & & & & \\
\hline
\end{tabular}

failure. The total proportion of subjects with their first episode of atrial fibrillation was 37.1 percent, and 63.4 percent of the qualifying episodes of atrial fibrillation lasted more than two days. There was no significant difference between the baseline characteristics of the two groups except for sex distribution; 42.5 percent in rhythm control group vs. 47.6 percent in the rate control group were women $(\mathrm{p}=$ $0.02)$.

\section{Outcome}

[Table 2] outlines the comparisons inthe risk of all-cause mortality, cardiovascular mortality, non-cardiovascular mortality, and hospitalization/ED visit between the two treatment groups. The risk of all-cause mortality (RR 1.34, 95\% CI 1.08-1.67; $\mathrm{P}=0.007)$ and non-cardiovascular death ( $\mathrm{RR} 1.91,95 \%$ CI 1.35-2.71; $\mathrm{P}<0.001$ ) were higher among rhythm-control subjects compared to ratecontrol subjects. These risks did not change after adjusting for sex distribution between the two groups. The risk of hospitalization/ED visits was also higher among the rhythm-control group (RR 1.10, 95\% CI 1.05-2.16; $\mathrm{P}=<0.001)$. However, there was no significant difference in cardiovascular mortalityamong the two treatment groups (RR 0.97, 95\% CI 0.71-1.32; P=0.823).

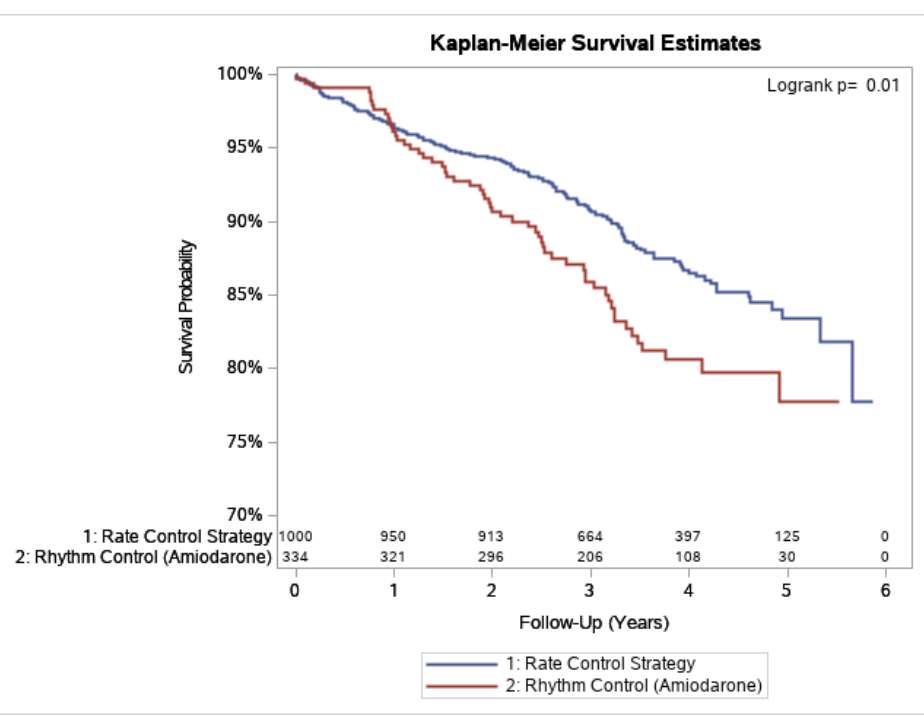
Rate Control.
[Table 3] compares the outcomes based on the type of the initial antiarrhythmic medications that was started after randomization. All-cause mortality was significantly higher among patients who received amiodarone as initial therapy (RR 1.39, 95\% CI 1.04-1.85; $\mathrm{P}=0.027)$ compared to patients who received rate-control therapy. In contrast, patients who received sotalol as an initial therapy (RR 1.09, 95\% CI 0.79-1.50; $\mathrm{P}=0.620)$ did not have an increase in all-cause mortality compared to patients who re-ceived rate-control therapy received rate-control therapy. [Figure 1] shows Kaplan Meier Survival for the differences in all-cause mortality between subjects in rhythm control strategy and subjects with rate control strategy for approximately six years of follow-up. Subjects who received rhythm control strategy had significantly shorter survival than subjects who received rate control strategy $(\mathrm{p}$-value $=0.01)$. [Figure 2] and Figure 3 show Kaplan Meier Survival for the differences in allcause mortality between amiodarone and sotalol compared to rate control strategy. Subjects who received amiodarone as initial rhythm control strategy had significantly shorter survival than subjects who received rate control strategy $(\mathrm{p}$-value $=0.01)$. However, there was no significant difference between in the survival between subjects who received sotalol as initial rhythm control strategy and subjects who received rate control strategy.

\section{Discussion}

In this subgroup analysis, rate-control and rhythm-control strategies were compared in patients with atrial fibrillation who had a normal or mildly enlarged left atrium. Despite this subgroup had a more favorable atrial substrate for to maintain sinus rhythm, attempts to pursue a rhythm-control strategy resulted in a higher risk of mortality and hospitalization/ED visits. The increased mortality in the rhythm-control group was primarily related to non-cardiovascular events. However, there was no significant difference in the risk of cardiovascular mortality in the two groups. These findings suggest that the mortality associated with a rhythm-control strategy is related to adverse effects of AADs.

The increase in adverse events is likely a result of the high rate of amiodarone use. In the rhythm-control group, $21.27 \%$ of patients had been started on amiodarone as the initial therapy after randomization. When we evaluated outcomes based on the type of antiarrhythmic medications used, we found that those who received amiodarone had higher rates of all-cause mortality (RR 1.39, 95\% CI $1.04-1.85 ; \mathrm{P}=0.027)$ compared to the rate-control group. This finding was driven by non-cardiovascular death (RR 2.13, 95\% CI 1.38-3.29; $\mathrm{P}=0.001)$. However, the second most common AAD used, sotalol, did not lead to an increased risk of all-cause mortality compared to rate-control group (RR 1.09, 95\% CI 0.79-1.50; $\mathrm{P}=0.620$ ).

Amiodarone's toxicities are well described, and its negative impacts have been demonstrated in previous clinical trials. The Rhythm of Rate Control in Atrial Fibrillation Pharmacological Intervention in Atrial Fibrillation (PIAF) study exclusively used amiodarone as its AAD. The trial found that patients in the rhythm-control group had a significantly higher rate of hospital admission and adverse events that led to a change in therapy ${ }^{[38]}$. The Polish How to Treat Chronic Atrial Fibrillation (HOT CAFE) Study used a stepwise algorithm 
of escalating AADs and cardioversion in the rhythm-control group. Ultimately 56 percent of patients in the rhythm-control group received amiodarone. Like the PIAF trial, the HOT CAFE trial found an increase in the rate of hospitalizations with amiodarone use ${ }^{[42]}$. The Japanese-RHYTHM Study randomized patients with paroxysmal atrial fibrillation, with most patients having normal to mildly enlarged left atria. The J-RHYTHM study found no increase in mortality or rate of hospitalization. In fact, rhythm control strategy was associated with fewer cardiovascular events than rate control strategy. The findings of this study are contrary to what had been observed in other trials likely due to the low rate of amiodarone use $(<1 \%)$ in this trial. This trial suggests that AADs other than amiodarone are better tolerated in patients when a rhythm-control strategy is pursued ${ }^{[43]}$.

\section{Supplementary materials}

Table 4:

Proportionate mortality in all patients with atrial fibrillation regardless the size of atrium, rhythm control vs. rate control.

\begin{tabular}{lllll}
\hline & $\begin{array}{l}\text { Rhythm } \\
\text { control } \\
(\mathrm{N}=356)\end{array}$ & $\begin{array}{l}\text { Rate } \\
\text { control } \\
(\mathrm{N}=310)\end{array}$ & $\begin{array}{l}\text { Relative Risk } \\
(95 \% \mathrm{Cl})\end{array}$ & P Value \\
& \multicolumn{2}{c}{ no. of patients $(\%)$} & & \\
Cardiovascular mortality & $171(48.44)$ & $182(51.56)$ & $0.82(0.71-0.94)$ & 0.006 \\
Non-cardiovascular mortality & $175(59.73)$ & $118(40.27)$ & $1.29(1.08-1.54)$ & 0.004 \\
\hline
\end{tabular}

Table 5: Incidence of the outcomes based on the size of atrium.*

\begin{tabular}{lll} 
& $\begin{array}{l}\text { Normal to mild atrial en- } \\
\text { largement }(\mathrm{N}=2022)\end{array}$ & $\begin{array}{l}\text { All patients regardless the size } \\
\text { of atrium }(\mathrm{N}=4060)\end{array}$ \\
All-cause mortality & $292(14.44)$ & $666(16.40)$ \\
Cardiovascular mortality & $149(7.37)$ & $353(8.69)$ \\
Non-cardiovascular mortality & $133(6.58)$ & $293(7.22)$ \\
$\begin{array}{l}\text { Hospitalization or Emergency } \\
\text { visit. }\end{array}$ & $1184(59.68)$ & $3058(75.32)$ \\
\hline
\end{tabular}

Table 6:

The model evaluates the effect of rhythm control after adjusting for sex distribution

\begin{tabular}{llll}
\hline & Adjusted OR & $\begin{array}{l}\text { 95\% Wald Confidence } \\
\text { Limits }\end{array}$ & Adjusted P-value \\
All-cause mortality & 1.40 & $1.09-1.80$ & 0.009 \\
Cardiovascular mortality & 0.96 & $0.69-1.34$ & 0.822 \\
Non-cardiovascular mortality & 1.96 & $1.35-2.84$ & $<0.001$ \\
\hline
\end{tabular}

The AFFIRM study included patients with atrial fibrillation with different atrial size, ranging from normal to severe atrial enlargement ${ }^{[40]}$. In this group of patients with different atrial size, patients who were on rhythm control had a higher proportionate mortality ratio of non-cardiovascular disease and lower proportionate mortality ratio of cardiovascular disease compared to patients who were in the ratecontrol group. The cardiovascular benefit of rhythm-control in this group neutralized the effect of non-cardiovascular side effect of antiarrhythmic medications. Therefore, the overall death rate was not significantly different between the rhythm-control and rate-control groups. In contrast, patients with normal or mild atrial enlargement did not have a significant cardiovascular benefit to neutralize the effect of non-cardiovascular mortality. Those patients did not have a significant cardiovascular benefit, in part, due to the lower rate of cardiovascular mortality ( $7.37 \%$ vs. $8.69 \%)$ compared to the pool of patients that include moderate to severe atrial enlargement.

Some limitations are worth mentioning. Although we include only patients with normal to mild LA enlargement, this was based on the LA dimension, which was the method that was used at that time.

Therefore, future studies should use LA volume divided by body surface area, which is reliable and the standard $2 \mathrm{D}$ echocardiographic method that is recommended by the American Society of Echocardiography to confirm the results of our study ${ }^{[50]}$.

\section{Conclusion}

This study demonstrated that rhythm-control strategy is associated with an increased risk of mortality and hospitalization in patients with normal to mild atrial enlargement. These findings were likely driven by amiodarone use in this subgroup.

\section{Disclosure}

None.

\section{References}

1. Wijffels, M. C., Kirchhof, C. J., Dorland, R., \& Allessie, M. A. (1995). Atrial fibrilla-tion begets atrial fibrillation. Circulation, 92(7), 1954-1968.

2. ALLESSIE, M. A. (1998). Atrial electrophysiologic remodeling: another vicious circle?. Journal of cardiovascular electrophysiology, 9(12), 1378-1393.

3. Frustaci A, Caldarulo M, Buffon A, et al. Cardiac biopsy in patients with "primary" atrial fibrillation. Histologic evidence of occult myocardial diseases. Chest. 1991;100:303-6.

4. Goette A, Honeycutt C, Langberg JJ. Electrical remodeling in atrial fibrillation. Time course and mechanisms. Circulation. 1996;94:2968-74.

5. Frustaci A, Chimenti C, Bellocci F, et al. Histological substrate of atrial biopsies in patients with lone atrial fibrillation. Circulation. 1997;96:1180-4.

6. Franz, M. R., Karasik, P. L., Li, C., Moubarak, J., \& Chavez, M. (1997). Electrical remodeling of the human atrium: similar effects in patients with chronic atrial fibrillation and atrial flutter. Journal of the American College of Cardiology, 30(7), 1785-1792.

7. Ausma J, Wijffels M, Thone F, et al. Structural changes of atrial myocardium due to sustained atrial fibrillation in the goat. Circulation. 1997;96:3157-63.

8. Ausma J, Wijffels M, van EG, et al. Dedifferentiation of atrial cardiomyocytes as a result of chronic atrial fibrillation. Am J Pathol. 1997;151:985-97.

9. Mihm MJ, Yu F, Carnes CA, et al. Impaired myofibrillar energetics and oxidative injury during human atrial fibrillation. Circulation. 2001;104:174-80.

10. Li Z, Hertervig E, Yuan S, et al. Dispersion of atrial repolarization in patients with paroxysmal atrial fibrillation. Europace. 2001;3:285-91.

11. Dudley SC, Jr., Hoch NE, McCann LA, et al. Atrial fibrillation increases production of superoxide by the left atrium and left atrial appendage: role of the NADPH and xanthine oxidases. Circulation. 2005;112:1266-73.

12. Atienza F, Almendral J, Moreno J, et al. Activation of inward rectifier potassium channels accelerates atrial fibrillation in humans: evidence for a reentrant mechanism. Circulation. 2006;114:2434-42.

13. Nattel S, Burstein B, Dobrev D. Atrial remodeling and atrial fibrillation: mechanisms and implications. Circ Arrhythm Electrophysiol. 2008;1:62-73. 
14. Attuel, P., Childers, R., Cauchemez, B., Poveda, J., Mugica, J., \& Coumel, P. (1982). Failure in the rate adaptation of the atrial refractory period: its relationship to vulnerability. International journal of cardiology, 2(2), 179-197.

15. BOUTJDIR, M., HEUZEY, J. Y., LAVERGNE, T., CHAUVAUD, S., GUIZE, L., CARPENTIER, A., \& PERONNEAU, P. (1986). Inhomogeneity of cellular refrac-toriness in human atrium: factor of arrhythmia?. Pacing and Clinical Electrophy-siology, 9(6), 1095-1100.

16. Rensma, P. L., Allessie, M. A., Lammers, W. J., Bonke, F. I., \& Schalij, M. J. (1988). Length of excitation wave and susceptibility to reentrant atrial arrhythmias in normal conscious dogs. Circulation research, 62(2), 395-410.

17. Ramanna H, Hauer RN, Wittkampf FH, et al. Identification of the substrate of atrial vulnerability in patients with idiopathic atrial fibrillation. Circulation. 2000;101:995-1001.

18. Nakao K, Seto S, Ueyama C, et al. Extended distribution of prolonged and fractionated right atrial electrograms predicts development of chronic atrial fibrillation in patients with idiopathic paroxysmal atrial fibrillation. J Cardiovasc Electrophysiol. 2002;13:996-1002.

19. Jais P, Hocini M, Macle L, et al. Distinctive electrophysiological properties of pulmonary veins in patients with atrial fibrillation. Circulation. 2002;106:247985.

20. Kalifa J, Jalife J, Zaitsev AV, et al. Intra-atrial pressure increases rate and organization of waves emanating from the superior pulmonary veins during atrial fibrillation. Circulation. 2003;108:668-671.

21. Aviles RJ, Martin DO, Apperson-Hansen C, et al. Inflammation as a risk factor for atrial fibrillation. Circulation. 2003;108:3006-10.

22. Xu J, Cui G, Esmailian F, et al. Atrial extracellular matrix remodeling and the maintenance of atrial fibrillation. Circulation. 2004;109:363-8.

23. Ishii Y, Schuessler RB, Gaynor SL, et al. Inflammation of atrium after cardiac surgery is associated with inhomogeneity of atrial conduction and atrial fibrillation. Circulation. 2005;111:2881-8.

24. Voigt N, Trausch A, Knaut M, et al. Left-to-right atrial inward rectifier potassium current gradients in patients with paroxysmal versus chronic atrial fibrillation. Circ Arrhythm Electrophysiol. 2010;3:472-80.

25. Henry WL, Morganroth J, Pearlman AS, Clark CE, Redwood DR, Itscoitz SB, Epstein SE. Relation between echocardiographically determined left atrial size and atrial fibrillation. Circulation. 1976; 53: 273-279.

26. Tsang, T. S., Barnes, M. E., Bailey, K. R., Leibson, C. L., Montgomery, S. C., Ta-kemoto, Y., ... \& Petty, G. W. (2001, May). Left atrial volume: important risk marker of incident atrial fibrillation in 1655 older men and women. In Mayo Clinic Proceedings (Vol. 76, No. 5, pp. 467-475). Elsevier.

27. Pritchett, A. M., Jacobsen, S. J., Mahoney, D. W., Rodeheffer, R. J., Bailey, K. R., \& Redfield, M. M. (2003). Left atrial volume as an index of left atrial size: a population-based study. Journal of the American College of Cardiology, 41(6), 1036-1043.

28. Zou R, Kneller J, Leon LJ, Nattel S. Substrate size as a determinant of fibrillatory activity maintenance in a mathematical model of canine atrium. Am J Physiol (Heart Circ Physiol). 2005; 289: H1002-H1012.

29. Oakes RS, Badger TJ, Kholmovski EG, et al. Detection and quantification of left atrial structural remodeling with delayed- enhancement magnetic resonance imaging in patients with atrial fibrillation. Circulation. 2009;119:1758-67.

30. Marchese, P., Bursi, F., Delle Donne, G., Malavasi, V., Casali, E., Barbieri, A., ... \& Modena, M. G. (2010). Indexed left atrial volume predicts the recurrence of non-valvular atrial fibrillation after successful cardioversion. European Journal of Echocardiography, 12(3), 214-221.

31. Wolf, P. A., Abbott, R. D., \& Kannel, W. B. (1991). Atrial fibrillation as an independent risk factor for stroke: the Framingham Study. Stroke, 22(8), 983-988.

32. Kannel, W. B., Wolf, P. A., Benjamin, E. J., \& Levy, D. (1998). Prevalence, inci- dence, prognosis, and predisposing conditions for atrial fibrillation: populationbased estimates. The American journal of cardiology, 82(7), 2N-9N.

33. Benjamin, E. J., Wolf, P. A., D’Agostino, R. B., Silbershatz, H., Kannel, W. B., \& Levy, D. (1998). Impact of atrial fibrillation on the risk of death. Circulation, 98(10), 946-952.

34. Ryder, K. M., \& Benjamin, E. J. (1999). Epidemiology and significance of atrial fi-brillation. The American journal of cardiology, 84(9), 131-138.

35. Go, A. S., Hylek, E. M., Phillips, K. A., Chang, Y., Henault, L. E., Selby, J. V., \& Singer, D. E. (2001). Prevalence of diagnosed atrial fibrillation in adults: national implications for rhythm management and stroke prevention: the AnTicoagulation and Risk Factors in Atrial Fibrillation (ATRIA) Study. Jama, 285(18), 2370-2375.

36. Miyasaka, Y., Barnes, M. E., Gersh, B. J., Cha, S. S., Bailey, K. R., Abhayaratna, W. P., ... \& Tsang, T. S. (2006). Secular trends in incidence of atrial fibrillation in Olmsted County, Minnesota, 1980 to 2000, and implications on the projections for future prevalence. Circulation, 114(2), 119-125.

37. Kirchhof, P., Bax, J., Blomstrom-Lundquist, C., Calkins, H., Camm, A. J., Cappato, R., ... \& Israel, C. W. (2009). Early and comprehensive management of atrial fibrillation: executive summary of the proceedings from the 2nd AFNET-EHRA consensus conference 'research perspectives in AF'. European heart journal, 30(24), 2969-2980

38. Hohnloser, S. H., Kuck, K. H., Lilienthal, J., \& PIAF Investigators. (2000). Rhythm or rate control in atrial fibrillation-Pharmacological Intervention in Atrial Fibrilla-tion (PIAF): a randomised trial. The Lancet, 356(9244), 17891794.

39. Van Gelder, I. C., Hagens, V. E., Bosker, H. A., Kingma, J. H., Kamp, O., Kingma, T., ... \& Crijns, H. J. (2002). A comparison of rate control and rhythm control in patients with recurrent persistent atrial fibrillation. New England Journal of Medicine, 347(23), 1834-1840.

40. Atrial Fibrillation Follow-up Investigation of Rhythm Management (AFFIRM) In-vestigators. (2002). A comparison of rate control and rhythm control in patients with atrial fibrillation. N Engl J Med, 2002(347), 1825-1833.

41. Carlsson, J. Ö., Miketic, S., Windeler, J. Ü., Cuneo, A., Haun, S., Micus, S., ... \& STAF Investigators. (2003). Randomized trial of rate-control versus rhythmcontrol in persistent atrial fibrillation. Journal of the American College of Cardiology, 41(10), 1690-1696.

42. Opolski, G., Torbicki, A., Kosior, D. A., Szulc, M., Wozakowska-Kaplon, B., Kolodziej, P., \& Achremczyk, P. (2004). Investigators of the Polish How to Treat Chronic Atrial Fibrillation Study. Rate control vs rhythm control in patients with nonvalvular persistent atrial fibrillation: the results of the Polish How to Treat Chronic Atrial Fibrillation (HOT CAFE) Study. Chest, 126(2), 476-86.

43. Ogawa, S., Yamashita, T., Yamazaki, T., Aizawa, Y., Atarashi, H., Inoue, H., ... \& Kamakura, S. (2009). Optimal treatment strategy for patients with paroxysmal atrial fibrillation. Circulation Journal, 73(2), 242-248. (J-RHYTHM)

44. Ionescu-Ittu, R., Abrahamowicz, M., Jackevicius, C. A., Essebag, V., Eisenberg, M. J., Wynant, W., ... \& Pilote, L. (2012). Comparative effectiveness of rhythm control vs rate control drug treatment effect on mortality in patients with atrial fi-brillation. Archives of Internal Medicine, 172(13), 997-1004.

45. Singh BN, Singh SN, Reda DJ, et al. Amiodarone versus sotalol for atrial fibrillation. N Engl J Med. 2005;352:1861-72.

46. Piccini JP, Hasselblad V, Peterson ED, et al. Comparative efficacy of dronedarone and amiodarone for the maintenance of sinus rhythm in patients with atrial fibrillation. J Am Coll Cardiol. 2009;54:1089-95.

47. Le Heuzey JY, De Ferrari GM, Radzik D, et al. A short-term, randomized, doubleblind, parallel-group study to evaluate the efficacy and safety of dronedarone versus amiodarone in patients with persistent atrial fibrillation: the DIONYSOS study. J Cardiovasc Electrophysiol. 2010;21:597-605.

48. Maintenance of sinus rhythm in patients with atrial fibrillation: an AFFIRM subs-tudy of the first antiarrhythmic drug. J Am Coll Cardiol. 2003;42:20-9. 
49. January CT, Wann LS, Alpert JS, et al. 2014 AHA/ACC/HRS guideline for the management of patients with atrial fibrillation: executive summary: a report of the American College of Cardiology/American Heart Association Task Force on practice guidelines and the Heart Rhythm Society. Circulation 2014;130:20712104.

50. ASE's Comprehensive Echocardiography E-Book (Kindle Locations 1108511086). Elsevier Health Sciences. Kindle Edition. 